\title{
BIOÉTICA E MATERIALISMO FILOSÓFICO: UM DIÁLOGO NECESSÁRIO
}

\author{
BIOÉTICA Y MATERIALISMO FILOSÓFICO: UN DIÁLOGO NECESARIO
}

BIOETHICS AND PHILOSOPHICAL MATERIALISM: A NECESSARY DIALOGUE

\author{
Antônio José Lopes Alves* \\ Sabina Maura Silva**
}

\begin{abstract}
RESUMO
Este artigo discute os principais vigamentos conceituais filosóficos que sustentam a proposta de pesquisa Revisão crítico-materialista da bioética, que se encontra em desenvolvimento pelos autores deste trabalho. Nele são desdobrados os temas e problemas envolvidos na elaboração de uma compreensão materialista das questões bioéticas. Argumenta-se não apenas da possibilidade, mas também da necessidade, de se pensar os desafios e dilemas bioéticos num quadro referencial diferente daquele dominante. A posição materialista aqui apresentada examina os temas da bioética partindo de uma compreensão crítica das suas determinações, de natureza histórico-social. A materialidade distintiva do humano, em todas as suas pressuposições, condições e formas de expressão, é o ponto de partida da reflexão aqui proposta. Neste, o humano é um modo material, concreto, mas bastante peculiar, de ser e de viver, que se distancia, não obstante perseverando em sua natureza material e vivente, daquele que caracteriza as formas imediatamente biológicas da animalidade.
\end{abstract}

PALAVRAS-CHAVE: Filosofia. Bioética. Materialismo. Sociabilidade. Humanização.

\section{RESUMEN}

Este artículo analiza los principales conceptos filosóficos que sustentan la investigación Examen Crítico-Materialista de la Bioética. Se despliega los problemas y las cuestiones del desarrollo de una comprensión materialista de las cuestiones de bioética. Se argumenta no sólo la posibilidad sino también la necesidad de pensar en los desafíos y dilemas bioéticos en un marco de referencia distinto que dominante. La posición materialista que aquí se presenta examina las cuestiones de bioética a partir de una comprensión crítica de sus determinaciones de carácter histórico y social. La materialidad distintiva del ser humano, en todas sus presuposiciones, condiciones y formas de expresión, es el punto de partida de la reflexión que aquí se propone. En esto, el ser humano es un hormigón forma material, pero bastante peculiar, de ser y de vivir, esa distancia, perseverando en su naturaleza material y viva, lo que caracteriza las formas biológicas de la animalidad.

PALABRAS CLAVE: Filosofía. Bioética. Materialismo. Sociabilidad. Humanización.

\footnotetext{
* Doutor (UNICAMP) e Mestre (UFMG) em Filosofia. Professor da UFMG: Colégio Técnico; Mestrado Profissional em Educação e Docência da UFMG. Membro do Comitê de Ética em Pesquisa da UFMG. Membro do Grupo de Pesquisa Marxologia: Filosofia e Estudos Confluentes, CNPq. E-mail: ajlopesalves@ gmail.com.

${ }^{* *}$ Doutora em Educação e Mestre em Filosofia (UFMG). Professora do Departamento de Educação CEFETMG. Coordenadora do Programa de Formação de Professores do CEFETMG. Docente e orientadora do Mestrado em Educação Tecnológica do CEFETMG. Membro do Grupo de Pesquisa Marxologia: Filosofia e Estudos Confluentes. E-mail: sabinamaura@gmail.com.
} 


\section{ABSTRACT}

This paper discusses the main philosophical conceptual frameworks that underpin the research proposal Review Critical-Materialist Bioethics, which is being developed by the authors of this work. It is deployed problems and issues involved in developing a materialist understanding of bioethical issues. It is argued not only the possibility but also the need to think about the challenges and bioethical dilemmas in a different frame of reference that dominant. The materialist position presented here examines bioethical issues starting from a critical understanding of their determinations of historical and social nature. The distinctive materiality of the human, in all its presuppositions, conditions and forms of expression, is the starting point of reflection proposed here. In this, the human is a material manner concrete, but rather peculiar, of being and living, that distance, nevertheless persevering in its material nature and living, that which characterizes immediately biological forms of animalit.

KEYWORDS: Philosophy. Bioethics. Materialism. Sociability. Humanization.

No presente artigo se expõe, sumariamente, os principais lineamentos teóricos que sustentam o projeto de pesquisa intitulado Revisão crítico-materialista da bioética. Iniciativa coletiva de investigação que conta para sua realização com apoio da Fundação de Amparo à Pesquisa do Estado de Minas Gerais (FAPEMIG), por meio de auxílio financeiro. A equipe de desenvolvimento do projeto em questão é composta por docentes, pesquisadores e estudantes, de diferentes departamentos, de três instituições de ensino superior de Minas Gerais: Universidade Federal de Minas Gerais, Pontifícia Universidade Católica de Minas e Centro Federal de Educação Tecnológica de Minas Gerais.

\section{I}

A proposta de investigação discutida no presente artigo tem como objetivo proceder a um exame crítico dos conceitos e temas centrais da reflexão bioética, a partir do arcabouço categorial produzido no interior dos quadros da tradição filosófica materialista, tendo por referência principal o pensamento marxiano. Nesse sentido, a produção marxiana, em suas diferentes fases de elaboração, se constitui no arrimo básico da propositura em tela e isso porquanto o conjunto dessa elaboração forneça alguns dos subsídios conceituais decisivos para a empreitada de uma renovação no que respeita à reflexão acerca dos problemas e questões levantados pela relação da ciência com a vida em geral, e a humana, em especial. Estando à base da pesquisa, a elaboração de Marx permite igualmente fixar alguns parâmetros que permitem a aproximação crítica da própria tradição do materialismo, bem como o 
ajuizamento das diversas posições baseado no paradigma do caráter essencial da sociabilidade para a compreensão das relações entre homem e natureza.

O que não exclui, muito ao contrário, a remissão a outros autores e momentos do materialismo anteriores e posteriores a Marx. A exercitação dessa revisão tem em vista a posição do edifício teórico da bioética sobre novos fundamentos. Para tanto, é mister pôr sob um olhar crítico rigoroso os pressupostos, de cunho predominantemente metafísico (transcendental e/ou religioso), que até o momento sustentam, de modo preponderante, os discursos e análises que têm por telos compreender filosoficamente consequências e dilemas do desenvolvimento das ciências e das tecnologias que se voltam ou intervêm na existência dos homens. Para tanto, algumas categorias basilares da reflexão bioética, tais como o de pessoa, identidade individual, alteridade, respeito e limites, etc., para não falar da própria eticidade, deverão ser objeto de cuidadoso escrutínio analítico, revelando tanto as pressuposições quanto implicações naquelas contidas. Abre-se a possibilidade de também inquirir as insuficiências e aporias das posições teóricas que as tomam em sua aparência imediata ou na forma de princípios autoevidentes. A propositura assim configurada exige que a própria questão da bioética seja reposta a partir de uma perspectiva nova, que se afaste seja das formulações arrimadas numa ética abstrata e idealista, seja daquelas de talhe naturalista. Posturas que encaminham a reflexão ética a soçobrar num moralismo estéril ou numa condenação in limine de todas as mediações práticas disponibilizadas pelo desenvolvimento da interatividade social e das transformações humanas, tanto no que concerne à sociabilidade quanto no que respeita à vivência individual. A dúplice resultante necessária é, de uma parte, a irrelevância que tais elaborações teóricas têm frente ao curso das alterações e, de outra, a ausência de uma formulação conceitual que possa de modo pertinente responder às demandas advindas dos processos de reinvenção e incremento da base da existência humana, deslanchada sob o impulso científico-tecnológico recente. Nesse âmbito, como assinala Sève (2000, p. 40): “[...] se o facto não funda o direito, o direito e a moral têm, por sua vez, grande dificuldade em estatuir sobre o facto biológico e terapêutico, doravante tão desconcertante". Descompasso tanto mais grave quanto mais reproduzido e ampliado pela disfonia de um discurso reflexivo cada vez mais assentado na mera retórica do interdito absoluto.

O que se carece, ao reverso, é da retomada de uma reflexão de caráter positivo, partindo do reconhecimento teórico do concretamente posto pelo ser e saber por meio dos quais os homens se afirmam e produzem sua existência social concreta. Contudo, não resulta 
disso um discurso acrítico ou laudatório do socialmente existente. Ao contrário, se põe como efetivamente crítico na medida em que tome a posição do humano como aquilo que é: resultante/pressuposto dinâmico da atividade produtiva, da criação e reprodução efetivas das condições objetivas da interatividade social. Nesse contexto, parte-se de uma compreensão da concretude objetiva da vida humana, da sua criação materialmente mediada pela atividade produtiva, da reconversão contínua de pressupostos e condições inicialmente naturais em formas de objetividade plasmadas no espaço delineado e determinado pelo conjunto dos nexos pressupostos e implicados na produção social da vida. As categorias que no contexto imediato do vivente natural são pressuposições unívocas tornam-se, no contexto das conexões humanas com a naturalidade, predicados efetivos sobre os quais se volta o conjunto da interatividade social. A biologia mesma do vivente humano se converte em matéria-prima inicial de sua atividade objetiva e materialmente configurada. Sem deixar de ser matéria viva, a objetividade biológica humana é resultante das formas de sua produção e reprodução sociais. O que coloca evidentemente a questão dos limites específicos do ser físico, físicoquímico, bioquímico, biológico, funcionalmente configurado no curso do processo de evolução por seleção natural. Preserva-se por certo sua natureza perecível, atravessada pela transitoriedade irremediável de processos reprodutíveis via metabolização, sua estabilidade relativa e frágil, entretanto ganha um caráter diferenciado no contexto do humano. Não se trata mais da pura entropia do inorgânico, nem da mediada falência temporal, defronte à qual somente a reprodução geracional pode fazer algo. A vida como processo de existência posto matricialmente pela relação com o externo e sua assimilação como insumo das funções, tem sua determinação progressivamente deslocada para a dação humana de forma à realidade objetiva, seja esta a ambiência propriamente natural, seja esta a efetividade do corpo humano vivo e ativo, pelas vias de seu comportamento conscientemente objetivo. Destarte, a vida humana é vida produzida, e vivida, humanamente. Como observa Chasin, citado por Vaisman (2001, p. XXIV), a este respeito, “a formação do ser social é um processo da animalidade à hominidade, o andamento da naturalidade à sociabilidade; o caminho infinito da naturalidade dada à sociabilidade não dada, em produção e reprodução perenes”. Apesar da aparente proximidade para com a expressão lukacsiana recuo das barreiras naturais ${ }^{1}$, a tese chasiniana dista em muito da suposição de uma dupla base, porquanto não se trata então apenas da

\footnotetext{
${ }^{1}$ Ver Lukács (2013, p. 221 e 239); bem como o volume II (2014), em especial no capítulo I "Trabalho".
} 
presença, mesmo que negativa, como limite, da naturalidade como tal, "dada", no ser e fazer humanos, mas da sua incorporação material socialmente mediada como objeto do humano em ato. Assim, o conjunto de propriedades e carecimentos objetivos não resta nos seres humanos em sua datidade imediata, como um natural a ser transformado, mas como um elemento material e objetivo da substância social, um predicado essencial, entretanto mutável e reconfigurável ad infinitum no curso da própria produção.

Desse modo, o ser carnal e sensível não é obviamente abolido, pois senão sequer esse seria o ser social, uma plenitude categorial objetivamente delimitada pela interatividade dos seres humanos em suas mais diversas formas de existência histórica. Os homens continuam carne, mas a carne é humana. Carecimentos, paixões, desejos, angústias, prazeres, dores, nervos, sangue, tecidos, células são todos esses elementos formas elementares humanas e humanizáveis indefinidamente. Abertura em sentido forte, tanto no que tange às possibilidades de Dasein quanto no quantum problemático, contraditório e, até talvez mesmo, aporético que desemboque na autoconstrução concreta, material, objetiva, do modo de ser propriamente humano. Por isso, não é o humano transcendental algo que forceje contra uma naturalidade dada e idêntica a si, univocamente biológico-animal, na imagem tão famosa como equivocada, embebida de preconceitos teológicos, do centauro ou do sagitário. É antes o processo de vida humana, de produção de coisas e de si no curso da transformação objetiva da realidade. De maneira alguma, um aposto ou uma "segunda natureza" simplesmente sobreposta a uma primeira, que restaria inalterada. Diversamente, trata-se da reelaboração da materialidade natural em materialidade humana. Matéria ativa e em atividade sobre o mundo e sobre si mesma, na forma duma atividade conscientemente realizada - o que não significa evidentemente, a plena consciência de ser ativo - que transforma em potência conformadora o que na animalidade despontava como força percipiente e de reatividade. Daí que até a ficção de uma consciência "pura" tornou-se possível (anima interpretada como fantasma na fantasia de uma "alma"), como consequência contraditória desse processo evolucionário-histórico de ir-sendo e devir-se humano.

No materialismo estamos e nele ficamos, até porque a "alma" nada mais é que a unidade sintética do vivenciado resultante do existir real e finito dos indivíduos, e não algum tipo de entidade puramente formal que se ajuntaria ao corpo. O que nos anima, e sua consciência individual de ser animado, é resultado/resultando do conjunto extremamente complexo e interconectado das séries de experiências reais individualizadas. Chasin aponta a 
partir de Marx para essa síntese atualmente existente que se demonstra na sua distinção ontológica frente aos demais viventes, sendo vivente, pelo seu comportar-se e se expressa também pelo ser-para-si deste comportar-se, o que tradicionalmente se chama "consciência". Não existe alma sem corpo e, humanamente em sentido pleno, corpo sem alma. Repita-se, no entanto, que não se trata de um “compósito" à moda aristotélica, "corpo e alma" ou "matéria e forma", mas de uma unidade sintética imediatamente existente de natureza histórico-objetiva. A alma não é então um "princípio" ao lado da - ou em oposição à - materialidade. Ao reverso disso, é ela um movimento ou atividade determinada da materialidade humana. A forma se forma pelas aventuras e desventuras da matéria humana; a alma se faz anima na medida em que o corpo é, vive, faz e acontece, como tal corpo particularmente humano; uma vez perdidas as condições materiais de ser especificamente humano, a alma se desvanece, esvai como um sopro, uma última oscitação quase sem conteúdo. O conteúdo verdadeiro ao tê-la tornado materialmente insustentável pode permanecer somente da única forma em que o morto vive: nos vivos, e por meio deles. Por isso, Chasin afasta de maneira explícita e peremptória qualquer traço da dualidade com que o senso-comum, porém não só ele, "pensa" o humano: não existem, pois, "instintos humanos", a não ser num oximoro impossível, porquanto expressa não uma contradição, porém tão somente um non-sense ontológico.

A distinção acima delineada apresenta consequências de monta para as próprias determinações do humano, bem como para o terreno das suas expressões ideais, entre elas, a da moralidade. Do entendimento do escopo determinativo da atividade produtiva - em sentido amplo - tem-se uma reformulação da própria relação entre cientificidade e ética, no interior da qual se postula a posição de uma eticidade intrínseca às próprias ciências como atividade humano-societária. O fato de o presente desenvolvimento das formas de produção das necessidades e dos carecimentos humanos, bem como dos meios de satisfazê-los, dar-se sob as determinações próprias da sociabilidade do capital deve evidentemente ser levado em consideração no ato mesmo da posição do problema. Ser engendrado e desdobrado de modo capitalista afeta de maneira objetiva e dramática o incremento dos meios de intervenção e remodelamento dos padrões biológicos, tanto no que concerne à individualidade humana, quanto às demais formas de viventes. O que não redunda, no entanto, na sua pura e simples identificação sem mais com o capital. Não obstante seja produzido, socialmente posto e assimilado sob a vigência das formas sociais do capital, não se segue daí o resultado de que aqueles desenvolvimentos - terapêuticos, farmacológicos, biotecnológicos, etc. - possuam 
como único horizonte a unilateralidade de funcionarem como mercadorias $^{2}$, de ser corpo do valor/mais-valor. Nesse sentido, a forma social, não obstante determine uma série de mediações da produção concreta, não necessariamente anula o caráter de valor de uso do produto. A tensão interna contraditória entre trabalho concreto e trabalho abstrato situado no interior da forma mercadoria não significa a vigência unilateral e/ou unívoca do segundo, ainda que aquele desempenhe evidentemente o papel de momento preponderante. Como essa preponderância categorial se efetiva no contexto particular das tecnologias médicas e das biociências, como reverbera no âmbito bioético, é uma das questões que aguardam definição teórica consistente. Algo que não se observa amiúde na reflexão contemporânea. Quando se verifica a tematização dos problemas bioéticos frente ao progresso das tecnociências biológicas, esta se dá de maneira abstrata, sem considerar o caráter histórico-particular da sociedade. Quando este último aparece referido, normalmente se o faz como necessidade externa, não conecta ao problema, ou então como uma expressão tácita de uma suposta natureza humana egoísta. A mercadoria, seus aspectos essenciais e circuitos de realização são tomados como existências dadas, sem história, diante das quais caberia simplesmente um conjunto de salvaguardas mitigadoras de seus efeitos. Por conseguinte, o que urge realizar é o entendimento de como a lógica particular do capital se expressa na produção e mobilização das ciências e das terapias, sem que estas sejam reduzidas simplesmente a mercadoria. É preciso entender como ser mercadoria afeta, e em que sentido, a existência das biociências e das tecnologias médicas.

\section{II}

Uma vez explicitados esses elementos categoriais distintivos, cabe esclarecer, igualmente de modo sumário, o caráter positivo, explicitamente proponente deste trabalho. De saída, torna-se importante clarificar o teor do materialismo que se propõe exercitar. Pois, conquanto se prospecte a leitura e o estudo estruturais e imanentes das diversas tradições do pensamento nas quais se expressaram problemas e temas conceituais concernentes à bioética, em especial naquela difusamente identificada sob a alcunha de materialista, parece ser mais

\footnotetext{
${ }^{2}$ Assim como, por um lado, o paciente assumir a figura do consumidor (BUENO, 2001, p. 15-18 e 44-56), ou por outro lado, simultaneamente, o tornar-se objeto de cuidados prévios e visando não simplesmente mais a cura, oferecido como um serviço de ponta, entre outros (PELLUCHON, 2014, p. 17-39).
} 
que pertinente trazer já à apreciação certas distinções demarcatórias. E nesse particular, o pensamento marxiano se revela frutífero ao indicar o marco de inflexão para com a tradição. Esse movimento de diferenciação com relação ao materialismo dominante na filosofia, já nas Teses ad Feuerbach, não obstante seu caráter aforismático, Marx indica alguns elementos que podem fazer parte dessa nova posição. Na oitava tese, superando a crítica que apenas se debruça sobre as fragilidades ou impropriedades teórico-conceituais ou dos valores verificadas nas elaborações tradicionais, o pensamento marxiano assevera que "toda vida social é essencialmente prática. Todos os mistérios (Mysterien), que induzem a teoria ao misticismo (Mystizism[us]), encontram sua solução racional (rationelle Lösung) na práxis humana e no compreender desta práxis" (MARX, 1969, p. 6). Em outros termos, para um adequado entendimento das questões mais prementes e candentes da vida social, um posicionamento que capture, apreenda e compreenda (begreif) as determinações mais essenciais da interatividade societária. Os problemas que emergem do específico comportamento humano prático social somente podem ser apreendidos em sua dimensão de efetividade quando sejam remetidos à forma social determinada que exerce o papel de momento preponderante como nexo ou liame principal que delimita e especifica as relações entre os homens. Nesse sentido, os mistérios que nascem e envolvem a prática humana apenas teriam sua resolução racional porquanto fossem teorizados a partir da compreensão da prática social determinada de um dado modo histórico de produção da vida humana e não tendo por arrimo uma suposta natureza humana - biológica ou transcendental - que tão somente se atualizaria na vivência objetiva. O que se propõe valer igualmente para os desenvolvimentos das tecnociências, bem como os desafios e equívocos que possam estar neles implicados. Estes últimos não se explicam pelo remetimento a uma vontade, a um impulso ou a uma pulsão de domínio da natureza, mas pelo entendimento das determinações da prática social concreta dos homens.

Desse modo, a posição materialista que arrima essa aproximação ao tema se norteia pelo reconhecimento da natureza da sociabilidade, ao mesmo tempo objetiva e resultante das interações entre os próprios indivíduos que delas participam. Social aqui não remete imediatamente às mediações ideais ou axiológicas, nem primariamente aos fenômenos subjetivos ou intersubjetivos. Diferentemente, é antes atinente às relações concretas havidas entre os indivíduos numa determinada configuração societária, nos quadros da qual vêm a surgir os elementos acima aludidos, como sua forma expressiva, mas nunca como 
determinações primárias de existência. As figuras ideais ou valorativas, num sentido intersubjetivo, se entendem, mesmo em seu papel de mediador ativo, como formas dum complexo relacional efetivo e assim vigoram. A sociabilidade é antes de tudo um factum relacional e precisa ser reconhecida em função das evidências concretas, da ordem inclusive do vivido, como uma determinação fundamental da existência dos indivíduos. Inexistente esta identificação, corre-se o risco de pôr como ficcional ou mesmo arbitrário o estatuto categorial de diversas ideias e noções importantes para o tratamento conceitual dos problemas bioéticos.

Como exemplo da possibilidade de exercitação deste padrão reflexivo materialista à bioética, referir-se-á aqui, também de modo sumário, o tratamento de uma das categorias centrais do discurso bioético: a de pessoa, conceito no qual, especialmente, sobressai-se o caráter problemático, transcendental e/ou mesmo religioso, que predomina nessa seara filosófica. A referida noção oferece um exemplo explícito da oscilação em que as elaborações teóricas em bioética incorrem entre dois extremos aparentemente opostos: o transcendentalismo (laico ou religioso) e o naturalismo. De um lado, a pessoa é determinada como uma entidade cujo lastro é conferido por um princípio de ordem transcendental, místico ou extramundano, que define a pessoalidade do indivíduo em termos de uma instância $a$ priori e virtualmente inacessível à experiência corrente. O humano do indivíduo, delimitado imediatamente pelo estatuto de sua pessoalidade, é considerado como uma esfera pairando acima da vida vivida ou oculta por detrás dela. A raiz da pessoa se situa então numa existência que não coincide imediatamente com sua individualidade particular, nem com os carecimentos ou desatinos a ela vinculados. É um momento transcendental, definidor da legitimação última da existência humana, terreno dos ideais da razão autônoma ou das leis que regem uma suposta essência imaterial herdada por participação incompleta no divino. De outra parte, considerada como acidente ou qualidade natural da individualidade biologicamente configurada, a pessoa é delimitada como um tipo de efeito ou consequência da existência física imediata. E isso comportando dois sentidos que podem paradoxalmente cruzar-se no terreno jurídico. Primeiramente, pode-se muito bem interpretar a pessoalidade como um epíteto amalgamado desde a concepção do indivíduo, ajuntado a ele por sua figura em trânsito de amadurecimento, por obra e graça da concepção. O que configuraria um dado caráter absolutamente primacial da pessoa como dignidade de princípio do ente humano e não uma situação que, não obstante privilégio dos indivíduos, somente poderia advir com o tempo e a maturação. Em segundo lugar, ao identificar como natural a posição da pessoalidade 
corre-se o risco exatamente de não se proceder a apreensão da especificidade concreta dessa determinação. Ou ainda de reduzir a concretude diretamente à materialidade em sua vigência mais imediata ou analógica. Radicar a pessoa no indivíduo, igualando-a, a ser humano numa acepção genérica é recolher sob esta rubrica “[...] tudo aquilo que é constitutivo do Homo sapiens sapiens: do neocórtex hiperdesenvolvido, como do polegar oponível, poder-se-á dizer que 'são humanos' - e há que dizê-lo, com certeza, neste sentido, do ser concebido da nossa espécie" (SÈVE, 2000, p. 30-31).

\section{III}

Frente a esse modus oscilatório entre o transcendente e o naturalismo abstrato há que apontar para a determinação da pessoalidade como caráter social dos indivíduos como algo que supera e integra num outro registro a existência natural, biologicamente imediata de uns para os outros. Na expressão mais simples e abstrata da sociabilidade, tomando-se dois indivíduos em relação por meio de suas mercadorias, evidencia-se que "ambos têm a necessidade de respirar; para ambos o ar existe como atmosfera; isso não os coloca em nenhuma relação social; como indivíduos que respiram, relacionam-se entre si apenas como corpos naturais, não como pessoas” (MARX, 2011, p. 186). Marx inclui aqui uma delimitação especificadora, uma forma de nexo social, que instaura a forma de ser dos indivíduos como reciprocidade social. Sociabilidade, mais que gregarismo, na medida em que a diversidade objetiva de carecimentos e objetos é posicionada como "o pressuposto de sua igualdade social no ato da troca e dessa conexão em que se relacionam como agentes produtivos". Forma de aparição imediata da sociabilidade a partir da qual pôde erigir-se todo um cabedal de supostos princípios e axiomas de natureza política e jurídica que se expressam na universalidade vazia das normas legais. Grande parte da perplexidade na qual se acha a reflexão jurídica doutrinária em razão de uma presumida natureza ficcional da pessoa - no âmbito do mundo do capital - advém desta relação de expressividade das formas concretas de aparecer da abstração do valor, naquelas do nível da normatização. Os indivíduos objetivamente aparecem (sie erscheinen) - e não apenas assim estes parecem ser - na superfície da trama da sociabilidade como simples cambistas. Relações que se revelam, não obstante a forte prevalência das suas formas de aparecer, por intermédio da analítica marxiana, como socialmente determinadas, nexos postos e circunscritos pelo registro da forma social essencial 
da produção da vida humana. O que evidencia teoricamente o fato de os indivíduos nessas relações mesmas estarem delimitados por um modo particular de coação societária. Processo social no qual, “[...] o indivíduo só tem existência social como produtor de valor de troca e que, portanto, já está envolvida a negação total de sua existência natural [...]” (MARX, 2011, p. 190-191). O constrangimento da alienação toma aqui, de chofre, a existência ainda muito simples e indeterminada de "um para outrem". No entanto, esse próprio ser para outro em sua singela simplicidade, porquanto seja já imediatamente ser para outro do valor de troca, é já determinado socialmente, uma forma de existência social dos indivíduos, que define sua pessoalidade, o existir de uns para os outros.

Esse problema reaparecerá em $O$ capital numa curiosa e instigante nota de comentários do Livro I, no primeiro item da parte Forma Valor Relativo, denominado Conteúdo da Forma Valor Relativo. Quando da análise da relação de valor, no curso da qual, abstratamente, uma mercadoria espelha (spiegelt) seu valor por meio do valor de uso de outra, Marx observa argutamente, na referida nota que:

\footnotetext{
De certa maneira, acontece aos homens como com as mercadorias. A não ser que ele venha ao mundo com um espelho, como filósofo fichtiano: eu sou eu, o homem deve primeiro espelhar-se em outros homens. Primeiramente, por meio do relacionamento com os homens, com Paulo, seu semelhante, que o homem Pedro, se relaciona consigo mesmo, como homem. Assim vale também para Paulo, em corpo e alma, em sua corporalidade paulina, como forma de aparição do gênero humano (MARX, 1998, p. 67).
}

A pessoalidade do indivíduo aparece aqui em sua totalidade, abarcando inclusive os modos nos quais se dá a constituição de uma dada identidade pessoal, como determinação posta pelo nexo ou relacionamento (Beziehung) social, o qual pode assumir diversas formas de relação proporcional ou recíproca (Verhältnis), às vezes extremamente complexas e contraditórias. No caso mais específico, a analogia se dá pela via da expressão do valor de dada mercadoria por meio do valor de uso de outra. Do tertium comum das mercadorias, o quantum socialmente necessário de tempo de trabalho, geral, pelo seu oposto, o conjunto de propriedades concretas e particulares. O que, no entanto, não autoriza a conclusão daquela (da linguagem das mercadorias) única via possível do relacionamento, nem mesmo a sua transformação em paradigma teórico, como pretende, por exemplo, Sève (2000, p. 40-47). Neste sentido, atente-se ao de certa maneira aposto ao início do texto, como determinante de escopo e validade, o qual delimita mesmo qualquer produtividade analógica compreensiva. 
Em outros termos, não se trata de conceber as determinações decorrentes da forma mercadoria como um paradigma analítico. Nem menos ainda de reduzir a pessoalidade a uma consequência direta do intercâmbio social ao modo das trocas de mercadorias. De todo modo, parece evidente a afirmação do caráter essencial dos liames societários, em suas formas concretas, para, num processo de espelhamento, dar-se a construção da pessoa. Espelhar-se que se arrima na presença irredutível e ontologicamente necessária do outro como outro. Ser pessoa é igualmente uma forma de processo de ser, processualidade social posta pelo conjunto de nexos constitutivos da sociabilidade e dos comportamentos estimulados, exigidos e possibilitados. E frise-se que tal processualidade se põe como definidora da pessoa em sua figura efetiva, passando a delimitar a corporalidade, como indicativo da totalidade, "corpo $e$ alma" (Haut und Haaren), do indivíduo. Nesse contexto, a pessoa não é um atributo aditado a uma suposta figuração primariamente natural ou biológica. No âmbito mesmo da objetividade, como corpo, a determinação social vige como forma do processo de contínuo devir humano dos indivíduos. Não se trata de uma característica naturalmente conferida ou herdade - na exata medida em que a identidade pessoal inexiste como pressuposição inata assim, ninguém vem ao mundo com um espelho. Nem cabe igualmente a suposição da pessoa como determinação transcendental, uma vez que também indivíduo algum é por nascimento filósofo, menos ainda filósofo fichtiano. Eu sou eu não me basta. A autoconsciência não é, pois, um dado ou pressuposto natural/ transcendentalmente conferido. E isto, porquanto seja a pessoa, em primeiro lugar, uma delimitação relacional e, em segundo lugar, seja também resultante de um espelhamento em que a figura do outro de igual generidade social esteja objetivamente pressuposta como elemento de um liame efetivamente concreto, determinado. A presença da alteridade, forma humana determinada da existência de cada um para todos e de todos para cada um, emerge como um espelho a possibilitar a formação da identidade pessoal, na proporção do desenvolvimento das relações sociais. Assim, eu somente me vejo a partir do espelhamento proporcionado pelo ser dos outros. A identidade do sujeito perde assim a qualquer aparência de ser autárquico e autossuficiente, remetido a uma suposta entidade individual, naturalmente conformada in totum e a priori à interação social. Forma pela qual foi, e ainda é preponderantemente entendida nos marcos da tradição filosófica ${ }^{3}$. Ao

\footnotetext{
${ }^{3}$ A esse respeito, o modo de concepção a priori se verifica tanto no empirismo (psicologismo) e no naturalismo biologicista, quanto nas correntes transcendentais do idealismo subjetivo, alterando-se somente a natureza ôntica do elemento pressuposto à autoidentidade individual (LOCKE, 1975, Livro I, Parte IV, Secção II e VI); bem como seus críticos contemporâneos, autodenominados animalistas (SCHECHTMAN, 1996).
} 
contrário, as interações em suas diversas modalidades, formas e contradições é que confere ao individual seu caráter imediatamente sintético. Decorre disso para a bioética que a categoria central da pessoa necessita ser entendida a partir da apreensão desse caráter social-objetivo da individualidade.

A sociabilidade aqui, não obstante em sua forma mais abstrata e simples, aparece como instância propriamente determinativa. Assim, o eu não tem em-si e por-si primariamente um espelho à disposição, o que interdita o solipsismo, pode encontrá-lo apenas no outro posto como figura irredutivelmente diferente, ainda que do mesmo gênero, para defrontá-lo. É apenas mediante um tipo qualquer de espelhamento relacional que pode emergir, em sua construção historicamente determinada - como deste ou daquele indivíduo -, o conjunto de marcas pessoais, ou ao menos os elementos que o delimitam, em ato e não como coisa inerte, um dado modo de ser pessoal. O caráter da pessoa se vê assim definido na dependência essencial e ineludível da sociabilidade, do conjunto de liames recíprocos objetivos, assumidos ou não conscientemente, pelas linhas dos quais se descreve um dado quadro social real. Na pessoa não é um animal humanizado, mas sim a construção objetiva em todos os seus aspectos do ente humano capaz de responder como si mesmo, mediado pelo seu específico comportamento ativo, que é engendrado, reproduzido, modificado, obstado, etc. no interior de determinado conjunto de relações. A própria biologia pode ser pensada como objeto, não obstante inicialmente dado e herdado, da atividade real de vir a ser ininterruptamente um ser humano em ato. O desenvolvimento não pode ser então tomado como atualização de uma essência unívoca, mas como existência efetiva em ato de determinadas propriedades plasmadas pela rede de relações, nas quais se encontram imersos, de saída, os indivíduos sociais.

O que, de maneira alguma, equivale a transformar o indivíduo em uma aparência ou "produto" "da" sociedade, um epifenômeno de "estruturas sociais" substancializadas ou, menos ainda, em delimitá-lo como um efeito "do meio". A este respeito, toma-se aqui como base materialista a pressuposição dos indivíduos reais vivos e ativos como a referência dos valores. Ou seja, uma existência indivisível na efetividade, equivalente aos "indivíduos humanos segundo o cânone de referência como aqueles que têm morfologia corpórea individual-elementar" (BUENO, 2001, p. 80). A figura concreta da singularidade humana permanece como uma divisa tanto para a prática quanto para o entendimento. Um ponto de partida que desloca necessariamente o centro de gravidade das questões para o ente social real 
e não em supostas formas puras a priori de uma eticidade universal abstrata. Aqui vale a remissão à forma concreta do Dasein a partir do que o pensador espanhol contemporâneo acima citado entende como individualidade canônica. Deste modo,

O caráter materialista deste princípio se observa no critério da individualidade corpórea que utiliza, e contrasta com as concepções bioéticas que partem da consciência, do espírito ou inclusive da persona indeterminada enquanto sujeito de direitos ou deveres, no que se abstraiu (ainda que não se tenha negado) seu caráter corpóreo. (BUENO, 2001, p. 80).

Por conseguinte, o que se deve determinar aqui é a forma pela qual esta figura concreta ganha vida e se faz uma síntese vivida imediata. Neste sentido, vale neste passo retomar a precisão conceitual marxiana segundo a qual o indivíduo é o ser social (MARX, 1968, p. 538-539). O social não existe como uma dimensão acima ou fora dos indivíduos, mas é o conjunto de suas relações sociais recíprocas, as quais ganham expressão objetiva na síntese individual. Existe imediatamente como forma viva individualizada e nesta determinidade objetivamente existe como um modo de ser diferente daquele biologicamente dado. Não se trata de duas essências - o individual e o social - lado a lado (ou mesmo, contrapostas numa antítese sem resolução), mas de dimensões da efetividade do sujeito humano; o indivíduo é uma síntese real e viva, vivendo em ato, um sendo específico de relações sociais. Por conseguinte, a reflexão bioética pode, porquanto parta dessa constatação, reposicionar de maneira mais produtiva e procedente as questões às quais é convocada a enfrentar no contexto complexo e altamente problemático das relações entre as práticas (médica, farmacológica, científica, tecnológica, etc.) que em alguma medida intervém na existência humana. Para tanto, o reexame crítico do que se entende por vida, e em especial, por vida humana, possibilitado pelo padrão do materialismo contemporâneo, arrimado na tradição fundada por Marx, ou menos dialogando com ela, pode encaminhar a posição mesma dos temas e categorias fundamentais sobre pressupostos diferentes daqueles predominantes nesta área de conhecimento/atuação. Exempli gratia, a categoria de pessoa humana não exibe mais traços de um mistério ou de uma mera ficção jurídica e se descortina em seu caráter eminentemente processual e social. Processualidade societária cuja démarche de seu teor histórico concreto interditaria as "soluções" transcendentais a priori e exigiria do pensamento que sobre aquela se volta um discernimento das particularidades engendradas pelo devir pessoa, tanto no nível individual, quanto naquele atinente aos contornos gerais que acabam se 
impondo na prática social e se tornam formas mais ou menos universais de constituição de autoidentidade e de responsabilização.

A proposta de investigação conceitual assim delineada e cotejada com o quadro de referenciais dominantes na área das discussões bioéticas permite desdobrar quatro complexos conceituais problemáticos. Primeiramente, aquele que tem por objeto o acervo contemporâneo tanto teórico quanto político-ideológico abrangido pela bioética. Em que medida a elaboração atualmente existente e em consolidação no campo bioético permite um diálogo com os pressupostos fundamentais do materialismo filosófico? Existem interseções categoriais ou pontos de contato produtivos a um debate profícuo? Caso a resposta seja afirmativa, quais correntes e/ou autores, dentro de quais subconjuntos temáticos e em quais contextos? $\mathrm{O}$ segundo perfilado problemático tem a ver com a delimitação categorial do ser vivo, em conexão com uma série de outras determinações conceituais, por exemplo, o que é espécie, tendo em vista a corroboração científico do evolucionismo? Questão fundamental a partir da qual se pode articular seja com o debate suscitado pelo desenvolvimento das ciências biológicas desde o evolucionismo no século XIX, seja com estudos históricos pelos quais se busque compreender criticamente a grande variabilidade de posições com relação às determinações essenciais do vivente. Em terceiro lugar, a perspectiva materialista pode também facultar a tentativa de elaboração crítica da história dos problemas bioéticos, e não somente da bioética como campo ou disciplina acadêmico-práticos. Existiria uma história das questões bioéticas que remontaria a momentos sociais e culturais diversos, que antecederiam o terreno da bioética propriamente dita? Enfrentavam também as sociedades em épocas anteriores à modernidade capitalista questões tipicamente bioéticas? Em que medida? Quais as aproximações e, principalmente, as diferenças essenciais da vivência de problemas acerca da medicina e da intervenção médica, entre aquelas experiências histórico-sociais específicas e a nossa? Finalmente, uma questão, não necessariamente exclusiva da bioética, muito menos nascida em seu horizonte: como se dá a relação entre o desenvolvimento das tecnociências contemporâneas, em seu incremento progressivo, e a vida cotidiana nas sociedades atuais? Como o mundo vivido apreende, assimila (se assim o fizer) e processa as transformações das técnicas, procedimentos e interações fármaco-medicinais modernas? Em que medida, se isso estiver acontecendo, as revoluções da cientificidade que estão à base da medicina contemporânea, altamente tecnológica, penetram na consciência média social cotidiana? São alguns desafios conceituais, mas com evidentemente peso político-ideológico, que outras 
perspectivas tentam igualmente defrontar. Entretanto, esposa-se aqui a posição de que talvez o materialismo, de extração marxiana, em função de suas pressuposições fundamentais, possa reformulá-las num sentido mais profícuo e menos abstrato. Compreender os dilemas, mesmo aqueles que quiçá se revelem insolúveis, em função do caráter de suas contradições, a partir do entendimento da efetiva vida social concreta, determinação fundante da individualidade e da personalidade, pode auxiliar o pensamento reflexivo na dura labuta de fornecer subsídios a uma prática socialmente responsável e individualmente plena de sentido.

\section{REFERÊNCIAS}

BUENO, G. O que és la bioética. Oviedo: Fundación Gustavo Bueno/Pentalfa Ediciones, 2001.

LOCKE, J. An essay concerning human understanding. Oxford: The Clarendon Press, 1975.

LUKÁCS, G. Para uma ontologia do ser social, volume I. São Paulo: Boitempo, 2013.

LUKÁCS, G. Para uma ontologia do ser social, volume II. São Paulo: Boitempo, 2014.

MARX, K. Grundrisse: esboços da crítica da economia política. São Paulo: Boitempo, 2011.

MARX, K. Das Kapital, erster Buch. Marx-Engels Werke, Band 23. Berlin: Dietz Verlag, 1998.

MARX, K. Ökonomische philosophische Manuskripte aus dem Jahre 1844. Marx-Engels Werke, Band 40,. Berlin: Dietz Verlag, 1968.

MARX, K. Thesen über Feuerbach. Marx-Engels Werke, Band 3. Berlin: Dietz Verlag, 1969.

PELLUCHON, C. L’autonomie briseé: bioéthique et philosophie. Paris: PUF, 2014.

SCHECHTMAN, M. The Constitution of Selves. Ithaca: Cornell University Press, 1996.

SÈVE, L. Para uma crítica da razão bioética. Lisboa: Instituto Piaget, 2000.

VAISMAN, Ester. Apresentação. Dossiê Marx: itinerário de um grupo de pesquisa. Ensaios Ad Hominem, Tomo IV. São Paulo: Estudos e Edições Ad Hominem, 2001. 